\title{
Association of Biochemical Markers, Hepatitis C Virus and Diabetes Mellitus in Pakistani Males
}

\author{
Muhammad Faisal Bashir ${ }^{1,2}$, Muhammad Saleem Haider ${ }^{3^{*}}$, Naeem Rashid ${ }^{1}$ and \\ Saba Riaz ${ }^{2,4}$ \\ ${ }^{1}$ School of Biological Sciences, University of the Punjab, Lahore 54590, ${ }^{2}$ Division of Molecular Pathology, Citi lab and Research \\ Centre, 525 A Faisal Town, Lahore, ${ }^{3}$ Institute of Agricultural Sciences, ${ }^{4}$ Department of Microbiology and Molecular Genetics, \\ University of the Punjab, Lahore 54590, Pakistan.
}

*For correspondence: Email: haider65us@yahoo.com, sabbb1502@yahoo.com; Tel: +924299231846

\begin{abstract}
Purpose: To investigate the association between Hepatitis $C$ Virus (HCV) infection and diabetes mellitus (DM), and the effects of these pathological conditions on some biochemical markers in Pakistanis.

Methods: A total number of 4717 chronic HCV patients were enrolled in this study out of which 4250 were positive with the enzyme linked immunosorbant assay (ELISA). Out of this, HCV was detected in 3513 samples by qualitative polymerase chain reaction (PCR). PCR positive samples were divided into: HCV without diabetes $(n=3136)$ and HCV with diabetes $(n=377)$ groups; 130 patients with diabetes only (negative for HCV ELISA) were also included in the study. Biochemical tests of all three groups were performed to determine liver, diabetic and lipid profiles.

Results: There was increased prevalence of HCV alone and HCV + diabetes patients in the $4^{\text {th }}$ decade of life. Alanine aminotransferase (ALT) titers were higher in HCV patients with diabetes than in HCV patients without diabetes ( $p \leq 0.001)$. Fasting blood glucose was greater in HCV patients with diabetes than in diabetes only patients. Total cholesterol and triglyceride were moderately lower in non-diabetic HCV patients than in diabetes only patients $(p \leq 0.005)$. However, total cholesterol and triglyceride levels were significantly higher in HCV patients with diabetes than in the other two groups $(p \leq 0.001)$. Conclusion: There is positive correlation of HCV with diabetes in the population studied. This association is more pronounced (where there are elevated levels of triglyceride and fasting blood glucose) in HCV patients with diabetes than diabetes patients without HCV infection.
\end{abstract}

Keywords: Hepatitis C, Diabetes mellitus, Biochemical markers, Lipid profile, Glycosylated haemoglobin

Tropical Journal of Pharmaceutical Research is indexed by Science Citation Index (SciSearch), Scopus, International Pharmaceutical Abstract, Chemical Abstracts, Embase, Index Copernicus, EBSCO, African Index Medicus, JournalSeek, Journal Citation Reports/Science Edition, Directory of Open Access Journals (DOAJ), African Journal Online, Bioline International, Open-J-Gate and Pharmacy Abstracts

\section{INTRODUCTION}

Hepatitis $\mathrm{C}$ virus (HCV) infection is a major public health problem and is the leading cause of hepatic cancer. There are about 170 million chronic HCV carriers throughout the world [1]. In Pakistan, the ratio of HCV carriers and infected patients is high $(30 \%)$ and is more than $20 \%$ in major Asian countries [2]. HCV mainly infects the liver but other tissues outside the liver can be involved, resulting in a wide spectrum of extrahepatic manifestations [3]. The onset of HCV infection is usually silent, and usually penetrates the other tissues of the body without obvious symptoms [4]. Extra-hepatic manifestations in patients with HCV infections include rheumatologic, dermatologic, diabetes and renal impairment [1]. 
It is believed that diabetes is one of the extrahepatic conditions attributable to HCV infection. Schlimovich et al [5] have argued that patients with diabetes have an increased risk of exposure to $\mathrm{HCV}$; the authors found abnormalities in glucose tolerance in $\mathrm{HCV}$ patients. History of $\mathrm{HCV}$ infection and advanced liver disease, such as cirrhosis and hepatoma are two important factors in diabetes mellitus and HCV association. Insulin resistance and glucose intolerance may also result from liver cirrhosis [6]. Diabetes mellitus may give raise to non-alcoholic fatty liver disease which could progress to cirrhosis and hepatocellular carcinoma. The severity of liver disease associated with HCV differs widely, as does the rate of progression towards the cirrhotic stage. The cirrhotic stage may depend on several, cofactors, such as age, gender, level of alcohol consumption, obesity, immune status and co-infections [7]. Diabetes changes the course of hepatitis $\mathrm{C}$ infection. It is possible that patients may develop insulin resistance independently, but clinical and experimental data suggest that $\mathrm{HCV}$ may contribute to its pathogenesis [8]. Treatment of diabetes in the cirrhotic patient is much more difficult because of liver damage and the hepatotoxicity of oral hypoglycemic drugs [9].

This study was designed to determine, if any, the association between HCV and diabetes.

\section{EXPERIMENTAL}

\section{Sample collection}

$\mathrm{HCV}$ infected serum samples were collected from patients already positive with $\mathrm{HCV}$ rapid test kit, or abnormal liver function test or with any clinical symptoms from various cities in Pakistan. The duration of sample collection was from January 2007 to December 2010. Serum samples (using vacutainer, BD Becton, Dickinson and Company, USA) of $\mathrm{HCV}$ alone, $\mathrm{HCV}+$ diabetes, diabetes alone and control were analyzed by HCV enzyme linked immunosorbant assay (ELISA) and HCV polymerase chain reaction (PCR), and for liver function tests, as well as for diabetic and lipid profiles. The study was approved by the Ethics Committee of Citi Lab and Research Centre, Lahore, Pakistan (ref no..CLRC-131/07) and followed international guidelines for human studies [10]. Patients were duly informed about the study and freely consented to participare in the study.

\section{ELISA test for anti-HCV antibody}

Test for anti-HCV antibody was performed by ELISA using a commercial kit (Micro LISA HCV Ab. Amgenix, USA). Ninety-six well plates were coated with antigen. Patient's blood serum was isolated and added into the wells before incubation. The plates were subsequently washed 5 times with phosphate buffered saline (PBS) and then horseradish peroxidase labeled mono-antibody was added. After incubation, the manufacturer's instructions were strictly followed; the plates were washed and the absorbance of the developed color was taken using an absorbance reader (microplate reader RT-6000 Rayto Company, Germany) at $450 \mathrm{~nm}$.

\section{HCV RNA isolation, cDNA synthesis and HCV PCR qualitative detection}

RNA from donor's blood sample was prepared according to the manufacturer's protocol with minor alteration in the phase separation step, viz, centrifugation time was reduced to $12 \mathrm{~min}$ from $15 \mathrm{~min}$ (Trizol. Invitogen, USA). The isolated serum $(300 \mu \mathrm{l})$ was mixed with $500 \mu \mathrm{l}$ of TRIzol reagent and extracted with chloroform and alcohol. After quantification, it was reverse transcribed into CDNA using antisense primers (Qaigen, Hilden Germany). Qualitative PCR of the five prime untranslated region (5' UTR) with appropriate primers was performed.

\section{Assessment of biochemical markers}

Clinical chemistry kits (Human, Germany) and automated biochemistry analyzer (Micro Lab 300 , Merk Germany) were used to analyze biochemical markers in serum. Diabetic profile, including fasting blood glucose (FBG), random blood glucose (RBG) and glycosylated haemoglobin (HbA1C), as well as lipid profile including cholesterol, triglycerides, high density ipoproteins (HDL) and low density lipoproteins (LDL) were among the biochemical markers analyzed. Liver profile, including alanine aminotransferase (ALT), aspartate aminotransferase (AST), alkaline phosphatase (ALP), gamma-glutamyltransferase $(\mathrm{Y}-\mathrm{GT})$, total bilirubin, total protein and albumin level were also evaluated.

\section{Statistical analysis}

Data was analysed using SPSS 18 version, Quantitaive data was presented in form of mean \pm S.D, Independent Sample t-test was applied to compare means of two groups and ANOVA was used to compare the means of more than 2 groups: $P \leq 0.05$ was considered as significant, $P$ $\leq 0.001$ was highly significant and $P>0.05$ was non-significant. 


\section{RESULTS}

A total number of 4717 suspected HCV males were enrolled in the study, out of which 4250 and 3513 were positive based on ELSIA and PCR, respectively. The results showed that participants with $\mathrm{HCV}$ only (without diabetes) were 3136 (86.08\%), HCV + Diabetes 377(10.36 \%) and diabetes only patients (negative for HCV ELISA) $130(3.56 \%)$. One hundred healthy participants were used as control.

The patients were grouped according to marital status. Married male participants accounted for 78.2, 83.2 and $90 \%$ for HCV only, HCV + diabetes and diabetes only groups, respectively, while 21.8, 16.7 and $10 \%$ unmarried patients were in $\mathrm{HCV}$ only, $\mathrm{HCV}+$ diabetes and diabetes only groups, respectively (Table 1). The patients were grouped according to age to see the prevalence of $\mathrm{HCV}$ only, $\mathrm{HCV}+$ diabetes and diabetes only patients in different decades of life of patients. The age groups, $30^{+}, 40^{+}$and $50^{+}$, accounted for HCV only (29.9\%), HCV + diabetes $(29.44 \%)$ and diabetes only (33.88 \%) patients, respectively (Figure 1). HCV qualitative PCR test was used to confirm HCV infection (Figure 2).

- HCV only \% HCV + Diabetics $\%$ - Diabetics only $\%$

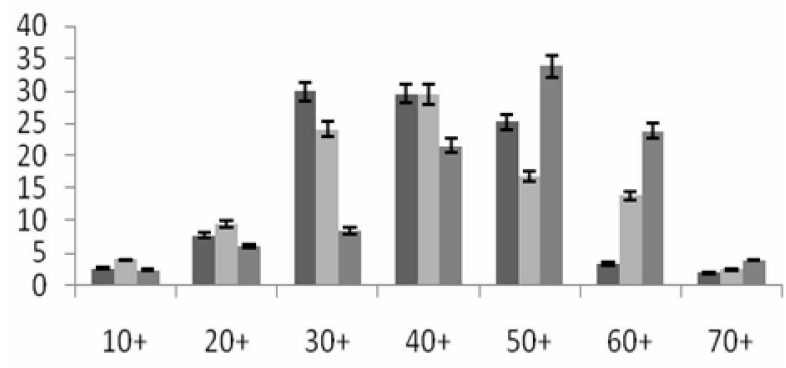

Figure 1: Sample groups according to the age of patients

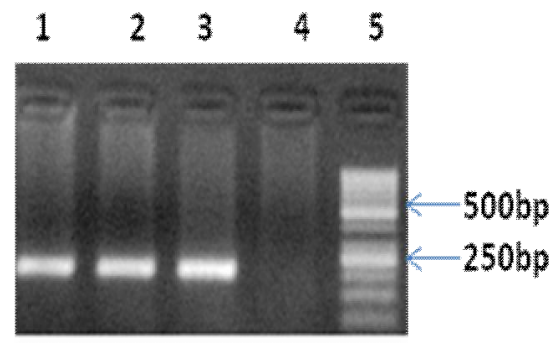

Figure 2: HCV qualitative PCR. Key: Lane $1=$ positive patient $A$, Lane $2=$ positive patient $B$, Lane 3 = positive control, Lane $4=$ negative control, Lane $5=$ marker

When liver function tests (LFTs) were analyzed $\mathrm{ALT}$ was raised in $\mathrm{HCV}$ alone and $\mathrm{HCV}+$ diabetes patients as compare to diabetes only patients. It was observed that ALT titer was more raised in $\mathrm{HCV}+$ diabetes patients than $\mathrm{HCV}$ only patients. Patients of $\mathrm{HCV}+$ diabetes group showed $26.36 \pm 0.36 \mathrm{U} / \mathrm{L}$ higher ALT levels than HCV only patients. ALT, AST and ALP were highly significant for $\mathrm{HCV}+$ diabetes group $(P \leq$ 0.001 ) and significant for HCV only group ( $P \leq$ 0.005 ) whereas these parameters were found nonsignificant $(P>0.005)$ for diabetes only patients. $\mathrm{Y}-\mathrm{GT}$ was significant for $\mathrm{HCV}+$ diabetes patients only $(P \leq 0.005)$. Albumin, bilirubin and total protein have not shown statistically any significant result in all three groups (Table 2).

Glycosylated haemoglobin (HbA1C) levels in married and unmarried $\mathrm{HCV}+\mathrm{DM}$ patients were identical. $\mathrm{HCV}+$ diabetes patients have shown more elevated levels of $\mathrm{HbA} 1 \mathrm{C}$, BGF and BGR than diabetes only patients. BGF and BGR showed highly significant difference for $\mathrm{HCV}+$ diabetes group $(P \leq 0.001)$ and significant difference for diabetes only group ( $P \leq 0.005$ ). $\mathrm{HbA} 1 \mathrm{C}$ showed significant difference for $\mathrm{HCV}+$ diabetes and diabetes only patients $(P \leq 0.005)$ (Table 3).

Among three groups, $\mathrm{HCV}+$ diabetes group showed a marked increase in serum cholesterol and triglyceride level than other two groups. It was observed that married patients had more raised levels of serum cholesterol and triglyceride levels than unmarried ones in all three groups. Cholesterol and triglyceride had shown highly significant difference for HCV + DM group $(P \leq 0.001)$ and significant for other two groups $(P \leq 0.005)$. On the other hand LDL was slightly higher than normal in HCV only group, relatively more raised in DM only groups while markedly raised in $\mathrm{HCV}+\mathrm{DM}$ group. Whereas LDL have shown significant difference for $\mathrm{HCV}+$ $\mathrm{DM}$ and DM only group ( $P \leq 0.005)$. HDL was observed insignificant for all three groups of patients $(P>0.005)$ (Table 4$)$.

Table 1: Sample groups categorized according to marital status of patients

\begin{tabular}{|c|c|c|c|c|c|c|}
\hline & \multicolumn{2}{|c|}{$\begin{array}{l}\text { HCV only } \\
(n=3136)\end{array}$} & \multicolumn{2}{|c|}{$\begin{array}{c}\text { HCV + diabetes } \\
(n=377)\end{array}$} & \multicolumn{2}{|c|}{$\begin{array}{c}\text { Diabetes only } \\
(n=130)\end{array}$} \\
\hline $\begin{array}{l}\text { No. } \\
\%\end{array}$ & $\begin{array}{c}\text { Married } \\
2451 \\
78.15\end{array}$ & $\begin{array}{c}\text { Unmarried } \\
685 \\
21.84\end{array}$ & $\begin{array}{c}\text { Married } \\
314 \\
83.28\end{array}$ & $\begin{array}{c}\text { Unmarried } \\
63 \\
16.71\end{array}$ & $\begin{array}{c}\text { Married } \\
117 \\
90\end{array}$ & $\begin{array}{c}\text { Unmarried } \\
13 \\
10\end{array}$ \\
\hline
\end{tabular}


Table 2: Effect of HCV and diabetes on liver functior parameters

\begin{tabular}{|c|c|c|c|c|c|c|c|c|c|}
\hline \multirow{2}{*}{$\begin{array}{l}\text { Liver } \\
\text { function } \\
\text { parameter }\end{array}$} & \multicolumn{3}{|c|}{ HCV only } & \multicolumn{3}{|c|}{ HCV+Diabetics } & \multicolumn{3}{|c|}{ Diabetics only } \\
\hline & $\begin{array}{l}\text { Married } \\
(n=2451\end{array}$ & $\begin{array}{l}\text { Unmarried } \\
(n=685)\end{array}$ & $p$ value & $\begin{array}{l}\text { Married } \\
(n=314)\end{array}$ & $\begin{array}{l}\text { Unmarried } \\
(n=63)\end{array}$ & $p$ value & $\begin{array}{l}\text { Married } \\
(n=117)\end{array}$ & $\begin{array}{l}\text { Unmarried } \\
(n=13)\end{array}$ & $p$ value \\
\hline ALT & $117.21 \pm 2.85$ & $114.35 \pm 4.75$ & $0.004^{*}$ & $143.56 \pm 3.21$ & $139.21 \pm 2.26$ & $0.001^{* *}$ & $19.34 \pm 0.47$ & $21.65 \pm 0.42$ & 0.235 \\
\hline AST & $102.63 \pm 3.52$ & $93.56 \pm 5.31$ & $0.003^{*}$ & $122.51 \pm 2.31$ & $116.21 \pm 1.62$ & $0.001^{* *}$ & $18.21 \pm 0.54$ & $20.25 \pm 0.35$ & 0.326 \\
\hline ALP & $417.64 \pm 11.32$ & $472.42 \pm 15.92$ & $0.002^{*}$ & $419.25 \pm 2.13$ & $481.65 \pm 5.61$ & $0.001^{\star *}$ & $251.35 \pm 8.56$ & $269.68 \pm 7.34$ & 0.015 \\
\hline Gamma GT & $107.52 \pm 4.51$ & $101.32 \pm 4.35$ & 0.009 & $115.32 \pm 1.25$ & $97.84 \pm 6.23$ & 0.002 & $16.23 \pm 1.25$ & $14.56 \pm 1.87$ & 0.318 \\
\hline Bilirubin & $1.23 \pm .08$ & $1.15 \pm .06$ & 0.023 & $1.29 \pm 0.07$ & $1.17 \pm 0.03$ & 0.010 & $0.54 \pm 0.09$ & $0.43 \pm 0.07$ & 0.542 \\
\hline T.Protein & $8.81 \pm 0.18$ & $8.67 \pm 0.57$ & 0.321 & $9.43 \pm 0.59$ & $9.08 \pm 0.41$ & 0.112 & $6.52 \pm 0.19$ & $6.78 \pm 0.35$ & 0.634 \\
\hline Albumin & $3.22 \pm 0.13$ & $3.18 \pm 0.11$ & 0.152 & $3.20 \pm 0.09$ & $3.12 \pm 0.07$ & 0.161 & $4.52 \pm 0.45$ & $4.47 \pm 0.41$ & 0.453 \\
\hline
\end{tabular}

Normal values: alanine aminotransferase $(A L T)<40 U / L$, aspartate aminotransferase $(A S T)<40 U / L$, alkaline phosphatase

$(A L P)<306 \mathrm{U} / \mathrm{L}$, gamma-glutamyltransferase (Gamma GT) < 40U/L, Bilirubin < 1mg/dl, T.Protein: 6-8.5 g/dl, Albumin: 3.4-

$4.8 \mathrm{~g} / \mathrm{dl}$, **Highly significant $P \leq 0.001$, *Significant $P \leq 0.005$

Table 3: Effect of HCV and diabetes on some serum parameters

\begin{tabular}{|c|c|c|c|c|c|c|c|c|c|}
\hline \multirow[b]{2}{*}{ Parameter } & \multicolumn{3}{|c|}{ HCV only } & \multicolumn{3}{|c|}{ HCV + diabetes } & \multicolumn{3}{|c|}{ Diabetes only } \\
\hline & $\begin{array}{l}\text { Married } \\
(n=2451)\end{array}$ & $\begin{array}{l}\text { Unmarried } \\
(n=685)\end{array}$ & $p$ value & $\begin{array}{l}\text { Married } \\
(n=314)\end{array}$ & $\begin{array}{l}\text { Unmarried } \\
(n=63)\end{array}$ & $p$ value & $\begin{array}{l}\text { Married } \\
(n=117)\end{array}$ & $\begin{array}{l}\text { Unmarried } \\
(n=13)\end{array}$ & $p$ value \\
\hline $\mathrm{HbA} 1 \mathrm{C}$ & $4.71 \pm 0.56$ & $4.45 \pm 0.43$ & 0.563 & $8.53 \pm 0.84$ & $8.04 \pm 0.63$ & $0.003^{*}$ & $7.51 \pm 0.42$ & $7.03 \pm 0.61$ & $0.004^{*}$ \\
\hline BGF & $95.46 \pm 1.52$ & $93.69 \pm 2.89$ & 0.264 & $195.63 \pm 3.21$ & $179.12 \pm 2.65$ & $0.001^{* *}$ & $180.39 \pm 4.35$ & $175.64 \pm 3.21$ & $0.003^{*}$ \\
\hline BGR & $169.23 \pm 2.13$ & $165.15 \pm 1.56$ & 0.342 & $305.62 \pm 5.72$ & $283.21 \pm 4.62$ & $0.001^{* *}$ & $279.65 \pm 4.96$ & $254.23 \pm 5.34$ & $0.004^{*}$ \\
\hline
\end{tabular}

Table 4: Effect of HCV and diabetes on serum lipid parameters

\begin{tabular}{|c|c|c|c|c|c|c|c|c|c|}
\hline \multirow[b]{2}{*}{$\begin{array}{l}\text { Lipid } \\
\text { parameter }\end{array}$} & \multicolumn{3}{|c|}{ HCV only } & \multicolumn{3}{|c|}{ HCV + diabetes } & \multicolumn{3}{|c|}{ Diabetes only } \\
\hline & $\begin{array}{l}\text { Married } \\
(\mathrm{n}=2451)\end{array}$ & $\begin{array}{l}\text { Unmarried } \\
(\mathrm{n}=685)\end{array}$ & p value & $\begin{array}{l}\text { Married } \\
(\mathrm{n}=314)\end{array}$ & $\begin{array}{l}\text { Unmarried } \\
(\mathrm{n}=63)\end{array}$ & $\begin{array}{l}p \\
\text { value }\end{array}$ & $\begin{array}{l}\text { Married } \\
(\mathrm{n}=117)\end{array}$ & $\begin{array}{l}\text { Unmarried } \\
13\end{array}$ & $p$ value \\
\hline Cholesterol & $221.52 \pm 1.87$ & $215.24 \pm 1.21$ & $0.004^{*}$ & $276.35 \pm 4.62$ & $245.63 \pm 6.23$ & $0.001^{* *}$ & $245.32 \pm 6.58$ & $220.98 \pm 4.32$ & $0.003^{*}$ \\
\hline Triglycerides & $207.21 \pm 2.45$ & $198.31 \pm 1.32$ & $0.004^{*}$ & $307.58 \pm 8.36$ & $235.19 \pm 4.37$ & $0.001^{* *}$ & $287.65 \pm 5.36$ & $215.63 \pm 4.21$ & $0.002^{*}$ \\
\hline $\mathrm{HDL}$ & $34.06 \pm 0.09$ & $34.59 \pm 0.08$ & 0.546 & $33.12 \pm 0.09$ & $33.59 \pm 0.12$ & 0.521 & $35.42 \pm 7.32$ & $36.12 \pm 4.16$ & 0.421 \\
\hline LDL & $146.02 \pm 1.36$ & $141.01 \pm 1.21$ & 0.423 & $181.72 \pm 2.34$ & $165.01 \pm 3.45$ & $0.004^{*}$ & $153.37 \pm 3.12$ & $141.74 \pm 2.93$ & $0.003^{*}$ \\
\hline
\end{tabular}

\section{DISCUSSION}

In this study, male Pakistanis were more infected with $\mathrm{HCV}$, as they were more exposed to risk factors such as blood transfusion, accidents, surgical operations, and shaving of beards with unsterilized instruments at barber salons [3]. Other risk factors such as multiple sexual relationships is also an important risk factor for HCV infections. Here, close association between $\mathrm{HCV}$ and diabetes was found in married males. Generally, diabetic HCV-infected males were in the $4^{\text {th }}$ and $5^{\text {th }}$ decades of their lives. This age group is highly exposed to risk factors of $\mathrm{HCV}$ and other extra-hepatic manifestations. Mason et al [11] documented that age and HCV infection were independent predictors for diabetes mellitus. Fraser et al [12] also suggested that both $\mathrm{HCV}$ infection and increasing age were independent risk factors for diabetes. It was reported that advance age is one of the most frequent risk factor for extra hepatic manifestation of HCV [13]. We observed higher prevalence of $\mathrm{HCV}$ parallels the higher incidence rates of diabetes. It was reported earlier that there are great chances of $\mathrm{HCV}$ patients to get diabetes [14].

It was observed that ALT and AST was relatively more raised in $\mathrm{HCV}$ and diabetic group than $\mathrm{HCV}$ alone group. Similarly, significantly elevated levels of ALT and AST in diabetic HCV patients than non-diabetic HCV patients were reported elsewhere [15]. Serum ALT was reported raised in $73.7 \%$ diabetic HCV patients than $18.5 \%$ diabetic patients without HCV infection [16]. Abnormal liver function tests have been reported by $\mathrm{HCV}$ diabetic patients [3]. $32 \%$ of $\mathrm{HCV}$ diabetic patients have shown raised level of ALT than $5 \%$ of diabetic patients without $\mathrm{HCV}$ 
infection [17]. Married patients of HCV only and HCV+DM groups showed raised AST levels. . ALT and AST levels increase up to 20 times but usually less than 5 times to upper limit of normal. Up to $40 \%$ of people with chronic HCV infection have normal ALT levels, even when tested on multiple occasions. ALT levels are usually higher than AST levels, but this may be reversed in patients with cirrhosis [18].

Alkaline phosphatase was high in both study groups. Generally, alkaline phosphatase and gamma glutamyl transpeptidase levels are usually not affected directly by $\mathrm{HCV}$ infections but there is a significant rise in gamma GT in liver cirrhosis. Total protein was higher while albumin was in both $\mathrm{HCV}$ alone and $\mathrm{HCV}$ diabetic groups and this is agreement with the results of Bacon et al [19]. It has been documented that HCV patients who develop diabetes show more severe liver disease based on biochemical markers and biopsy findings [20]. Mansour et al [15] reported that BGF, BGR and $\mathrm{HbA} 1 \mathrm{C}$ were significantly higher in $\mathrm{HCV}$ diabetic patients than in non-diabetic HCV patients and these results are in agreement with our findings. Hence, HCV infection may adversely influence diabetes prognosis. A consequence of adverse prognosis, is poor renal functions [21]. HCV infection has a link with insulin resistance and diabetes. Abnormal glucose tolerance was $28 \%$ in chronic liver disease patients [16].

Researchers have revealed that $\mathrm{HCV}$ eradication increases insulin sensitivity which reduces incidence of diabetes [18]. A possible mechanism has been suggested for $\mathrm{HCV}$ and diabetes association. HCV core protein induces changes in signaling in the pathway of insulin. This change affects $\beta$-cells and hence there is decrease in the secretion of insulin and this causes a rise in blood glucose level [8]. Lower total cholesterol and triglyceride have been reported to be higher in HCV patients than in diabetes patients without HCV infection [15] and this has been buttressed by the findings of the current study. HCV diabetic patients have been reported to show elevated triglyceride levels [22] and this is in agreement with the findings of our study but was different from that of Casqueiro et al [18]. This may be due to changes in the cellular pathways of triglyceride metabolism in HCV patients with diabetes. Disturbance in lipid profile indicates increased level of inflammation or altered caloric metabolism, resulting in difficulty in survival [23].

\section{CONCLUSION}

There is significant correlation between hepatitis $\mathrm{C}$ virus infection and diabetes. Both aggravate each other. Serum ALT and triglyceride are important parameters in this correlation. Further studies should throw more light that would help to improve the clinical management of diabetes patients with $\mathrm{HCV}$ infection.

\section{ACKNOWLEDGEMENT}

This study formed part of the PhD work of one of the authors, Muhammad Faisal Bashir. The work was funded by Higher Education Commission of Pakistan.

\section{REFERENCES}

1. Wang $C$, Wang $S$, Yao W, Chang $T$, Pesus $C$. Community-based Study of Hepatitis C Virus Infection and Type 2 Diabetes: An Association Affected by Age and Hepatitis Severity Status. Am J Epidemiol 2003; 58: 1154-1160.

2. Bashir MF, Haider, MS, Rashid N, Riaz S.. Distribution of hepatitis $C$ virus (HCV) genotypes in different remote cities of Pakistan. Afr J Microb Res 2012; 6: 4747-4751.

3. Hussnain R, Koukabm G, Qayyum M, Asim M, Khanum A. Association of Diabetes with Hepatitis C. Virus (HCV) Infected Male and Female Patients Along with Different Risk Factors. Inter J Agri Bio 2007; 9: 736-740.

4. Salomon JA, Weinstein MC, Hammitt JK, Goldie SJ. Empirically calibrated model of hepatitis $C$ virus infection in the United States. American J. Epidemiol 2002; 156: 761-73.

5. Shlimovich PB, Zus'BA, Evdokimov AR. Clinical picture and pathogenesis of Diabetes Mellitus in Chronic Hepatitis and Cirrhosis of the liver. Probl Endokrinol 1977; 23(4): 7-14.

6. Compean DG, Jaquez-Quintana J, Maldonado-Garza H. Liver cirrhosis and diabetes: Risk factors, pathophysiology, clinical implications and management. World J Gastroenterol 2009; 15(3): 280-288.

7. Asselah $T$, Rubbia-Brandt $L$, Marcellin $P$, Negro $F$. Steatosis in chronic hepatitis C: why does it really matter? Gut, 2006; 55: 123-130.

8. Negro F, Alaei M. Hepatitis $C$ virus and type 2 diabetes. Worl J Gast 2009; 15(13): 1537-1547.

9. Nishida T, Tsuji S, Tsujii M, Arimitsu S, Haruna $Y$, Imano $E$, Suzuki M, Kanda T, Kawano S, Hiramatsu N, Hayashi N, Hori M. Oral glucose tolerance test predicts prognosis of patients with liver cirrhosis. Am J Gastroenterol 2006; 101:7075.

10. The NuGO Bioethics Guidelines on Human Studies, 2007 [cited 2008 Apr 20]. Available from http://nugo.dife.de/bot/.

11. Mason A. Viral induction of type 2 diabetes and autoimmune liver disease. J Nutr 2001; 131 (10): 2805S-2808S.

12. Fraser GM, Harman I, Meller $N$, Niv $Y$, Porath $A$. Diabetes mellitus is associated with chronic hepatitis $C$ but not chronic hepatitis $B$ infection. Isr J Med Sci 1996; 32(7): 526-30.

13. Cacoub P, Renou C, Rosenthal E, Cohen P, Loury I: EH manifestations associated with $\mathrm{HCV}$ infection. A prospective multicenter study of 321 patients. The 
GERMIVIC Groupe d'Etude et de Recherche en Medicine Interne et Maladies Infectieuses sur le Virus de l'Hepatite C. Medicine 2000; 79: 47-56.

14. Lecube AC. Hernandez J. Genesca JI. Esteban R, Simo $R$. High prevalence of glucose abnormalities in patients with hepatitis $C$ virus infection: a multivariate analysis considering the liver injury. Diabetes Care. 2004; 27: 1171-1175.

15. Poordad F, McCone J Jr, Bacon BR. Boceprevir for untreated chronic HCV genotype 1 infection. N Engl J Med 2011; 364: 1195-1206.

16. Bacon BR, Gordon SC, Lawitz E. Boceprevir for previously treated chronic HCV genotype 1 infection. N Engl J Med 2011; 364: 1207-1217.

17. Petit JM, Bour JB, Galland-Jos C, Minello A, Verges B, Guiguet M: Risk factors for diabetes mellitus and early insulin resistance in chronic hepatitis C. J Hepatology 2001; 35: 279-283.

18. Casqueiro J, Casqueiro J, and Alves C. Infections in patients with diabetes mellitus: $A$ review of pathogenesis. Indian J Endocrinol Metab. 2012; 16: 27-36.
19. Caronia S, Taylor K, PaBgliaro L, Carr Z, Palazzo U, Petrik Jl: Further evidence for an association between noninsulin-dependent diabetes mellitus and chronic hepatitis $C$ virus infection. Hepatology 1999; 30: 1059-1063.

20. Jacobson IM, McHutchison JG, Dusheiko GM. Telaprevir for previously untreated chronic hepatitis C virus infection. N Engl J Med. 2011; 364: 24052416.

21. Thuluvath PJ, John PR. Association between hepatitis $C$, diabetes mellitus, and race: a case-control study. American J. Gastroenterol 2003; 98: 438441.

22. Samantray J, Zambare S, Seyoum B, Abou-Samra AB. Glucose control and lipid metabolism in African American patients with type 2 diabetes mellitus and chronic hepatitis C viral infection. Endocr Pract. 2011: 17: 363-368.

23. Jacobson IM, McHutchison JG, Dusheiko GM. Telaprevir for previously untreated chronic hepatitis C virus infection. N Engl J Med. 2011; 364: 24052416. 